\title{
A equidade como política
}

$\mathrm{U}$ ma das premissas componentes do sistema público universal de saúde é sua permeabilidade para as demandas advindas da sociedade, que se formam, historicamente, na pujança das relações sociais que estruturam e conformam a dinâmica social.

O CEBES renova seu papel como parte integrante do movimento sanitário, atuando na busca e construção de uma sociedade em que a saúde é entendida como dimensão integrante da vida e resultante da democracia baseada na igualdade das relaçóes em sociedade.

Atualmente, são vívidos e crescentes o anseio e a necessidade de retomada das bases políticas e dos princípios da Reforma Sanitária como projeto para uma sociedade que promova e respeite os direitos sociais e humanos dos seus grupos e coletivos. O movimento pelos direitos sociais e humanos ressurgiu com força nas manifestaçôes populares ocorridas em 2013, e o CEBES vem acompanhando e participando de perto por meio de análises conjunturais e ação política.

A construção do Sistema de Saúde brasileiro enfrenta desafios crescentes na concretização do acesso e qualidade dos serviços. Nas duas últimas décadas, o tema da saúde da população negra tem se caracterizado pela demanda por melhoria da saúde e do atendimento oferecidos a segmentos da população em desvantagem social. Essa condição desfavorável é gerada tanto pelas relaçôes econômicas desiguais como pelo racismo estrutural e simbólico, ambos cultural e historicamente instalados na sociedade brasileira, permeando todas as áreas de atuação humana, inclusive a da saúde.

Os artigos temáticos que compõem este número da Revista Saúde em Debate trazem para a discussão pesquisas, avaliações e experiências sobre a saúde da população negra e a persistência das desigualdades e iniquidades étnico-raciais. Mais do que um campo de investigação, a saúde da população negra não se restringe apenas à questão da produção de conhecimento sobre um problema real. Configura-se numa ânsia por melhoria de condiçóes de vida e de saúde que requer um sistema de atenção à saúde capaz de atender integralmente às especificidades que se manifestam na população. Tais especificidades estão associadas a práticas e atitudes marcadas pela exclusão étnico-racial, com frequência considerada inexistente. Entretanto, a visibilidade estrutural alcançada por tal anseio nestes últimos anos, tanto nos movimentos sociais como na academia e nas políticas governamentais, deve ser creditada à força e organização política dos seus atores.

A 'racialização' que o movimento negro e os grupos acadêmicos incorporaram em suas análises tem natureza histórica. Não é uma invenção transplantada de outros lugares, mas um processo histórico secular de acontecimentos e debates 
que hoje culminam em políticas de açóes afirmativas mais factíveis e amplas. Pode ser difícil comparar mais de um século de conquistas da população negra brasileira com duas décadas de ação afirmativa no Brasil, porém, a 'racialização', que agora atravessa a área da saúde, é o caminho que segmentos da sociedade brasileira escolheram, mesmo que não estejam isentos de equívocos ou acertos, o que justifica ainda mais a necessidade de estudar, debater e conhecer.

Há, dentre os teóricos brasileiros, aqueles que sustentam posiçóes críticas à 'racialização' da sociedade brasileira retomada nos anos 1990 com a multiplicação de políticas para populaçốes negras. $\mathrm{O}$ argumento principal é o de que o modelo histórico de relaçóes étnico-raciais no Brasil é diferente daquele vivido nos EUA ou na África do Sul, que nossas classificações raciais são múltiplas e não estritamente bipolares entre negros e brancos.

A complexidade étnico-racial da sociedade brasileira, contudo, não a isentou de uma hierarquização social perversa e de consequências culturais duradouras, produzindo privilégios e exclusões, reforçando as desigualdades sociais e econômicas, enfim, gerando claro impacto sobre as formas de adoecimento e morte nessas populaçóes que hoje são bem estudadas. $\mathrm{O}$ acesso e a qualidade dos serviços de saúde ainda revelam tratamento diferenciado a negros e não negros, como se fossem cidadáos de primeira e segunda categorias.

É imperativo que se respeitem as experiências e sentidos daqueles que se autoclassificam como negros no Brasil. Não é mera classificação, mas posição política oriunda de experiência de vida que lhes permite escolher o caminho que desejam para suas vidas e de seus coletivos. É o direito à autodeterminação política e cultural para alcançarem padróes de existência mais justos. Por isso, é fundamental que se construa uma agenda capaz de promover a investigação sobre a saúde da população negra e o racismo institucional para que o sistema universal de saúde absorva as demandas da população.

Alguns artigos deste número analisam, também, o acesso aos serviços de saúde como indicador de avaliação da equidade do sistema. Apesar dos avanços ocorridos na última década na ampliação e oferta dos serviços, as condiçôes práticas que favorecem o atendimento - denominado acessibilidade por alguns autores - continuam apresentando grande fragilidade, principalmente quanto à presença de profissionais de saúde, tempo de espera para atendimento, disponibilidade de exames complementares e o importante trabalho de cuidado que envolve a promoção, prevenção e recuperação. $\mathrm{O}$ atendimento ainda carece de políticas consistentes para sua sustentabilidade. 
É importante reafirmar que acesso não é a simples abertura de novo serviço; requer planejamento estrutural e epidemiológico, capacitação da equipe do serviço, articulação com a rede local de saúde, assim como as demandas advindas do envolvimento da sociedade civil organizada. O acesso é um conjunto de decisões, financiamento e medidas que exigem mudança de cultura política e organizacional.

O CEBES nasceu com os movimentos sociais e populares e continua a dialogar com a sociedade e suas demandas de forma a transformar estruturas e viabilizar o projeto de equidade para a sociedade brasileira. Em sua trajetória de construção da Reforma Sanitária, o CEBES tem analisado criteriosamente os eventos e problemas da saúde. Com este número, o CEBES privilegia o tema Saúde da População Negra, reforçando, mais uma vez, a aliança com os segmentos que se encontram em situação de desigualdade e exclusão em quaisquer de suas possíveis dimensôes históricas. Esta é a democracia que perseguimos e que pode produzir reais mudanças sociais e na saúde.

Nelson Mandela vive. Viva Mandela! 